\title{
Acute Esophageal Necrosis
}

\author{
Daniel C. Butler, Nicholas I. Batalis
}

Acad Forensic Pathol. 2017 7(2): 312-316

\section{AUTHORS \\ Daniel C. Butler MD, Medical University of South Carolina - College of Medicine}

Roles: Project conception and/or design, data acquisition, analysis and/or interpretation, manuscript creation and/or revision, approved final version for publication, accountable for all aspects of the work.

Nicholas I. Batalis MD, Medical University of South Carolina - Department of Pathology and Laboratory Medicine

Roles: Project conception and/or design, data acquisition, analysis and/or interpretation, manuscript creation and/or revision, approved final version for publication, accountable for all aspects of the work.

CORRESPONDENCE

Daniel C. Butler MD, 96 Jonathan Lucas St, Charleston SC 29425-2503, butlerdc@musc.edu

ETHICAL APPROVAL

As per Journal Policies, ethical approval was not required for this manuscript

STATEMENT OF HUMAN AND ANIMAL RIGHTS

This article does not contain any studies conducted with animals or on living human subjects

STATEMENT OF INFORMED CONSENT

No identifiable personal data were presented in this manuscsript

DISCLOSURES \& DECLARATION OF CONFLICTS OF INTEREST

Nicholas I. Batalis is the Associate Editor-in-Chief of Academic Forensic Pathology: The Official Publication of the National Association of Medical Examiners. The authors, reviewers, and publication staff do not report any other relevant conflicts of interest

FINANCIAL DISCLOSURE

The authors have indicated that they do not have financial relationships to disclose that are relevant to this manuscript

KEYWORDS

Forensic pathology, Esophageal necrosis, Black esophagus, Natural disease, Low salt state

INFORMATION

ACADEMIC FORENSIC PATHOLOGY: THE OFFICIAL PUBLICATION OF THE NATIONAL ASSOCIATION OF MEDICAL EXAMINERS

C2017 Academic Forensic Pathology International • (ISSN: 1925-3621) • https://doi.org/10.23907/2017.028

Submitted for consideration on 14 Jan 2017. Accepted for publication on 6 Mar 2017 
Acute esophageal necrosis (AEN), or "black esophagus," is a rare, sometimes deadly medical entity that presents endoscopically with diffuse and circumferential pigmentation of the esophagus and histologically with mucosal necrosis. Two retrospective case series $(1,2)$ and a one-year prospective study described incidences of $0.28 \%$ and $0.2 \%$, respectively (3). Acute esophageal necrosis is most prevalent in elderly men $(2,4,5)$, with one series of 88 cases reporting that only $18.6 \%$ of the affected patients were female (4).

The pathogenesis of AEN is poorly understood but likely involves hemodynamic instability combined with compromised mucosal defense secondary to poor nutritional status due to comorbidity $(5,6)$. Acute esophageal necrosis almost always involves the distal esophagus with abrupt demarcation at the gastroesophageal junction (4), a feature explained by the distal esophagus' poor vascularity relative to the upper and middle thirds. Acute esophageal necrosis typically occurs in the context of multiple comorbid conditions that promote both hypoperfusion and overall poor nutritional status, such as cardiovascular disease, chronic kidney disease, and malignancy $(4,5)$. Despite this common association, other insults have been described as causes of AEN, including toxic injury, trauma, and infection (2). Given the common blood supply of the celiac trunk, concurrent duodenal pathology may also be present along with AEN, which may exacerbate mucosal injury by creating gastric obstruction and consequent reflux of gastric contents. Clinically, these patients are most often hospitalized for signs of upper gastrointestinal bleeding followed by cardiovascular insult, epigastric pain, and vomiting $(5,6)$.

Histologically, AEN presents with mucosal necrosis and the absence of viable epithelium. Necrosis is most often confined to the mucosa; however, it may extend to the submucosa and even invade through the muscularis propria (7). Other possible findings include capillary thrombi and inflammatory changes with cellular infiltrates (4).

Mortality associated with AEN has been reported as high as $34.5 \%$; however, death is generally attributed to secondary medical conditions rather than AEN itself (2). In one series, direct fatal manifestations of AEN occurred in $5.7 \%$ of patients and included perforation, mediastinitis/abscess, and superinfection (4).

The case presented highlights the characteristic features of AEN. A 62-year-old, nonobese female was found dead on the floor of her residence. She had a medical history significant for hypertension, chronic obstructive pulmonary disease (COPD), and mixed hyperlipidemia. Several days prior to her death, she complained of nausea and vomiting. At autopsy, the esophageal mucosa was strikingly thin, friable, and with a black discoloration extending superiorly from a well-demarcated line at the gastroesophageal junction to the mid-esophagus (Images 1 and 2). Histology of the esophagus showed full-thickness necrosis, mucosal sloughing, and a brisk mixed inflammatory infiltrate covered by a thin film of brown-black pigment that was sharply delineated from the adjacent, normal appearing gastric mucosa (Images $\mathbf{3}$ and 4). Additionally, the decedent was found to have an enlarged heart $(450 \mathrm{~g})$ with atherosclerotic narrowing of the right coronary artery $(75 \%)$ and left anterior descending artery $(90 \%)$. Her lungs were also found to be hyperinflated with emphysematous changes. Vitreous electrolytes were performed and revealed the following: sodium, $102 \mathrm{mmol} / \mathrm{L}$; potassium, $13.3 \mathrm{mmol} / \mathrm{L}$; chloride, $70 \mathrm{mmol} / \mathrm{L}$; urea nitrogen, $22 \mathrm{mg} / \mathrm{dL}$; creatinine, $0.5 \mathrm{mg} / \mathrm{dL}$; and glucose, $<5 \mathrm{mg} / \mathrm{dL}$.

The cause of death was certified as low-salt state due to acute esophageal necrosis. The decedent had multiple comorbidities, including cardiovascular disease and COPD, which likely lowered her threshold for hemodynamic insult and led to AEN. Reportedly, she suffered from nausea and vomiting for several days prior to death, which is a known presentation of AEN. Her vitreous electrolytes support this presentation, showing severely depressed sodium and chloride concentrations with only a moderate elevation in potassium, a pattern most characteristic of a low-salt state (8). While the direct insult leading to her AEN is unknown, her multiple comorbidities most likely created a state favorable for hypoperfusion, resulting in AEN and associated severe vomiting that led to a low-salt state and ultimately, death. 


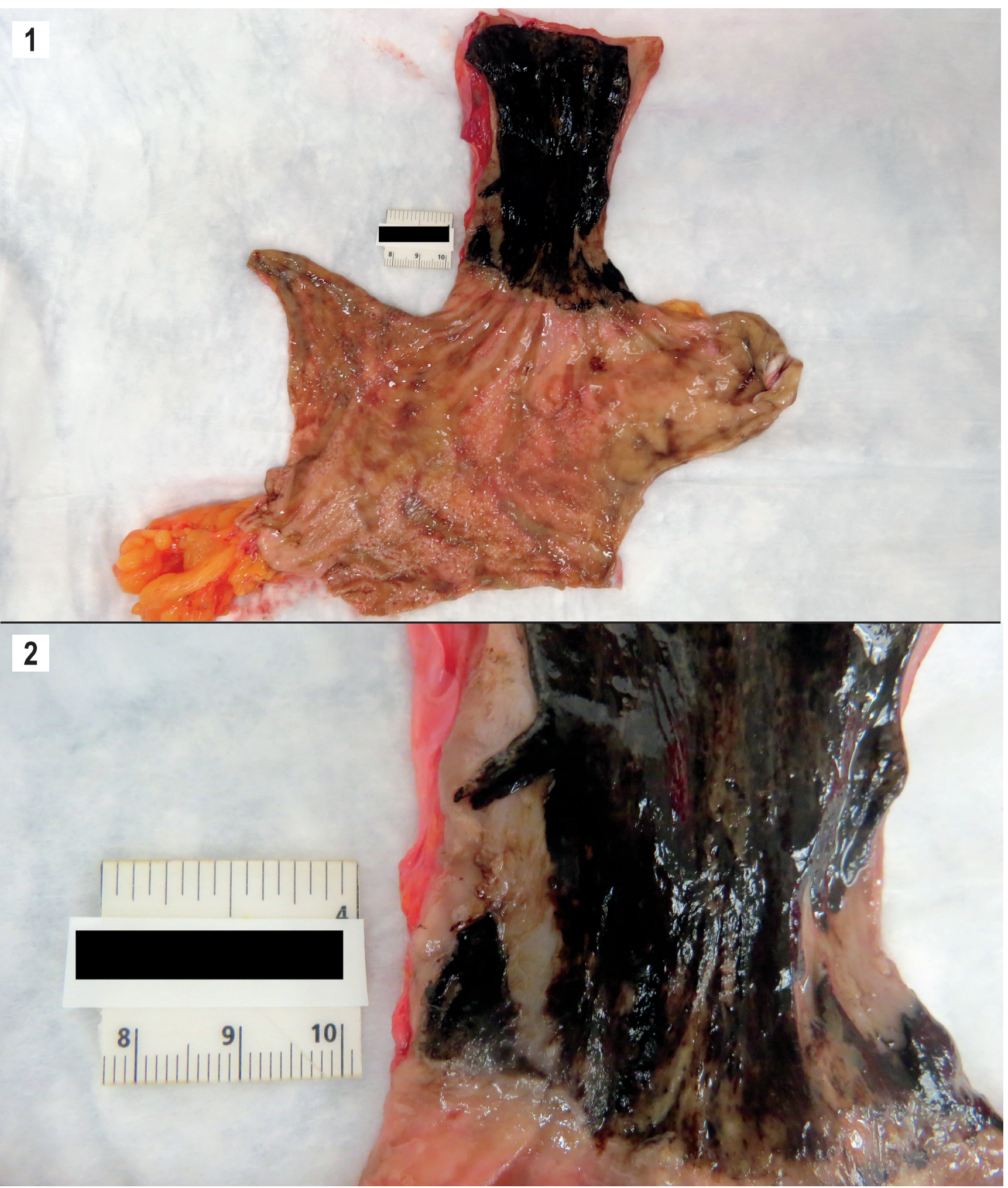

Images 1 and 2: Gross photographs showing black, friable esophageal mucosa that terminates abruptly at the gastroesophageal junction.

\section{Page 314}

Butler \& Batalis - Acute Esophageal Necrosis

ACADEMIC FORENSIC PATHOLOGY: THE OFFICIAL PUBLICATION OF THE NATIONAL ASSOCIATION OF MEDICAL EXAMINERS

(C2017 Academic Forensic Pathology International

Downloaded from www.afpjournal.com by an AFP Journal subscriber

This article is for personal use only and may not be shared or distributed in any fashion 


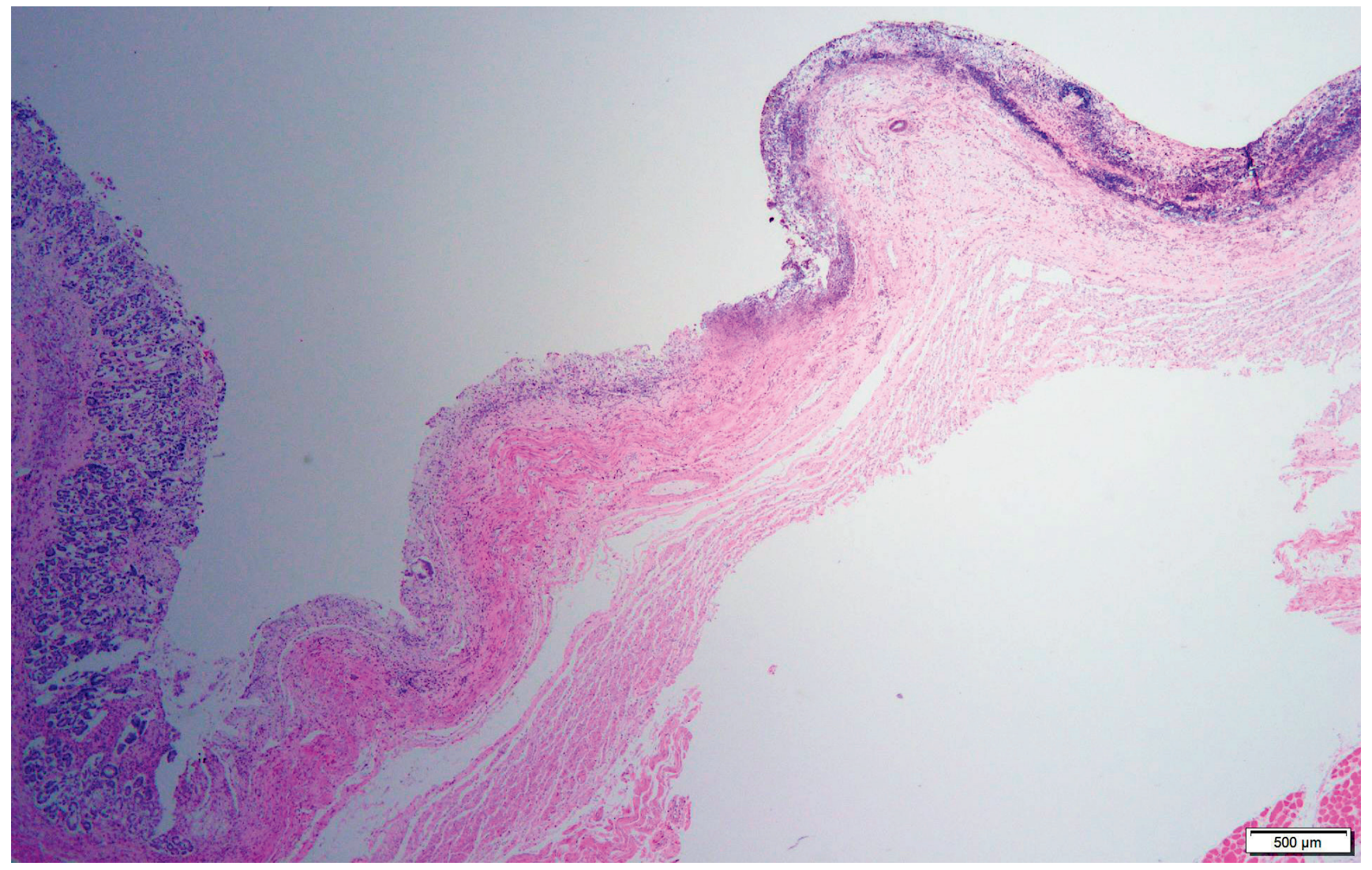

Image 3: Low-power photomicrograph of the gastroesophageal junction showing relatively normal gastric mucosa on the left, with a transition to denuded and necrotic esophageal mucosa on the right (H\&E, x20). 


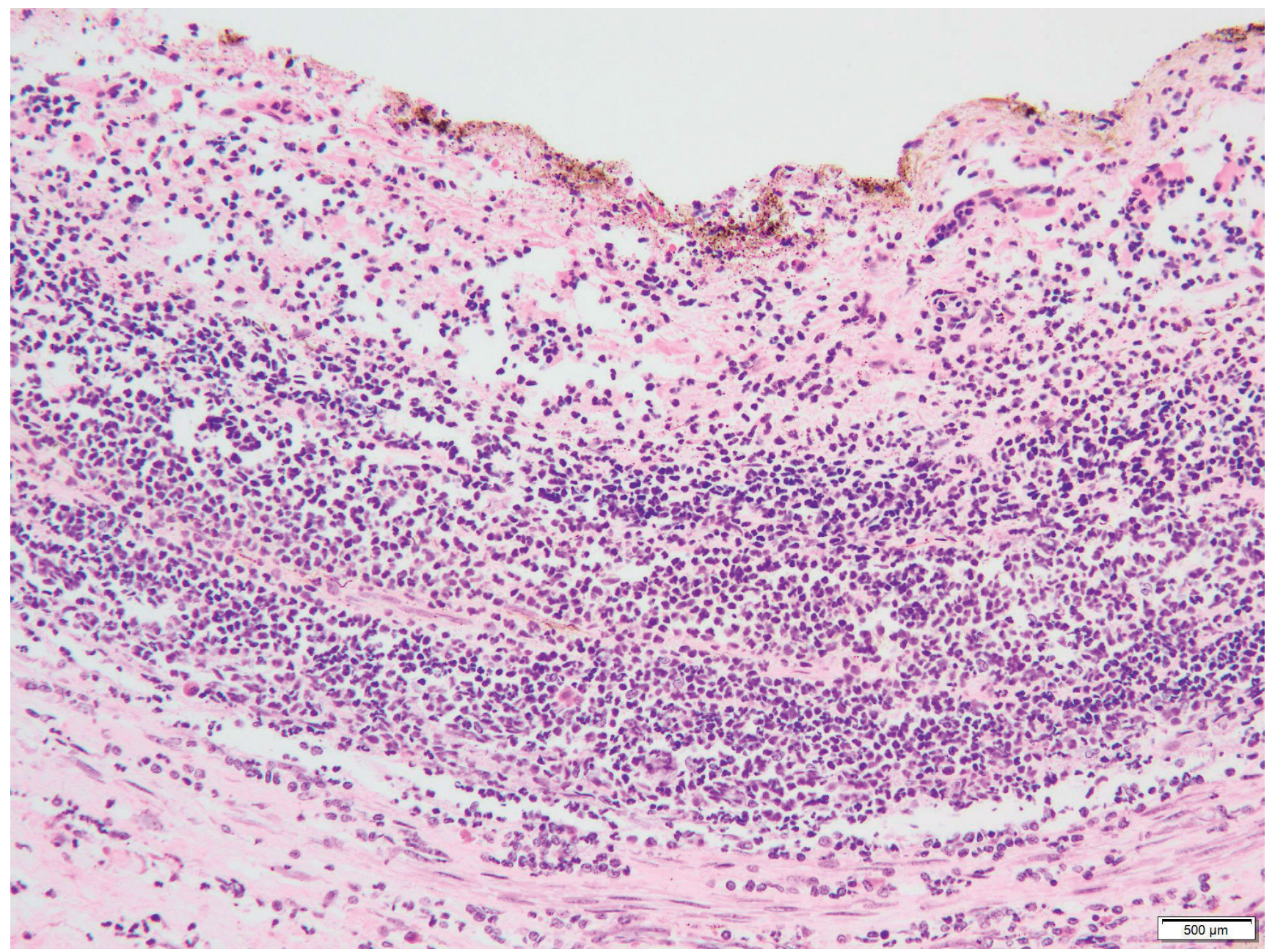

Image 4: High-power photomicrograph of the esophageal mucosa showing ulceration, necrosis, and a brisk inflammatory infiltrate covered by a thin film of brown-black pigment (H\&E, x200).

\section{REFERENCES}

1) Ramos R, Mascarenhas J, Duarte $P$, et al. [Acute esophageal necrosis: a retrospective case series]. Rev Esp Enferm Dig. 2008 Sep; 100(9):583-5. Spanish. PMID: 19025311.

2) Augusto F, Fernandes V, Cremers MI, et al. Acute necrotizing esophagitis: a large retrospective case series. Endoscopy. 2004 May; 36(5):411-5. PMID: 15100949.

https://doi.org/10.1055/s-2004-814318.

3) Ben Soussan E, Savoye G, Hochain P, et al. Acute esophageal necrosis: a 1-year prospective study. Gastrointest Endosc. 2002 Aug; 56(2):213-7. PMID: 12145599.

https://doi.org/10.1016/s0016-5107(02)70180-6.

4) Gurvits GE, Shapsis A, Lau N, et al. Acute esophageal necrosis: a rare syndrome. J Gastroenterol. 2007 Jan; 42(1):29-38.

PMID: 17322991. https://doi.org/10.1007/s00535-006-1974-z.
5) Gurvits GE, Cherian K, Shami MN, et al. Black esophagus: new insights and multicenter international experience in 2014. Dig Dis Sci. 2015 Feb; 60(2):444-53. PMID: 25297468. https://doi.org/10.1007/s10620-014-3382-1.

6) Gurvits GE. Black esophagus: actue esophageal necrosis syndrome. World J Gastroenterol. 2010 Jul 14; 16(26):3219-25. PMID: 20614476. PMCID: PMC2900712. https://doi.org/10.3748/wjg.v16.i26.3219.

7) Jacobsen NO, Christiansen J, Kruse A. Incidence of oesophageal necrosis in an autopsy material. APMIS. 2003 May; 111(5):591-4. PMID: 12887512 https://doi.org/10.1034/j.1600-0463.2003.1110509.x.

8) Coe JI. Postmortem chemistry update. Emphasis on forensic application. Am J Forensic Med Pathol. 1993 Jun; 14(2):91-117. PMID: 8328447. https://doi.org/10.1097/00000433-199306000-00001. 